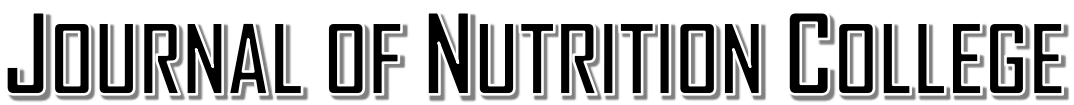

Volume 6, Nomor 1, Tahun 2017, Halaman 43-51

Online di : http://ejournal-s1.undip.ac.id/index.php/jnc

\section{PERBEDAAN PERILAKU MAKAN DAN POLA ASUH PEMBERIAN MAKAN ANTARA BALITA GEMUK DAN BALITA NON GEMUK DI KOTA SEMARANG}

\author{
Dienny Zata Yumni, Hartanti Sandi Wijayanti*) \\ Program Studi Ilmu Gizi Fakultas Kedokteran Universitas Diponegoro \\ Jln. Prof. H. Soedarto, SH., Semarang, Telp (024) 8453708, Email : gizifk@undip.ac.id
}

\begin{abstract}
Background: Obesity was not only found in adults but also in children. Eating Behaviours and parenting feeding styles were two factors which affect children's nutritional status, so the role of parents was very important to resolve obesity by controlling children's daily intake. The aim of this study was to analyze differences in eating behaviours and parenting feeding styles and between obese and non-obese children in Semarang.

Method : Research design was case control. Research subject were pairs mother and children under five, consisted of 22 subjects of case group (obese) and 22 control group subjects (non-obese). The study was conducted in Bangetayu Kulon and Jangli Village, Semarang. Data about eating behaviors and parenting feeding styles were obtained through a questionnaire. Data was analyzed using Chi-square categorical comparative test.

Result : Almost all of subject in obese group had high food approach score (95.5\%), while in non-obese group nothing subject with high food approach score (0.0\%). Meanwhile, food avoidant score was high in non-obese group (72.7\%), whereas obese group with high food avoidant score only 27.3\%. Parenting feeding style that dominant in obese group was neglect type (59.\%), while in non-obese group was democratic type (54.5\%). There were differences in food approach ( $p<0.01)$, food avoidant behaviour ( $p=0.007)$, and parenting feeding style $(p<0.01)$ between the two groups.

Conclusion: There were differences in food approach behavior, food avoidant behaviour, and parenting feeding style between obese and non-obese children in Semarang.

Key words : children under five, obese, eating behaviour, parenting feeding style
\end{abstract}

\begin{abstract}
ABSTRAK
Latar Belakang : Kegemukan kini tidak hanya ditemukan pada orang dewasa saja melainkan juga pada anak balita. Pola asuh pemberian makan dan perilaku makan balita merupakan dua faktor yang dapat mempengaruhi status gizi balita, sehingga peran keluarga khususnya ibu sangat penting untuk mengatasi kasus kegemukan dengan mengontrol asupan makan anak sehari-hari. Tujuan penelitian ini adalah menganalisis perbedaan pola asuh pemberian makan dan perilaku makan antara balita gemuk dan balita non gemuk di Kota Semarang.

Metode : Subjek penelitian adalah pasangan ibu dan balita berusia dua sampai lima tahun yang terdiri dari 22 subjek kelompok kasus dan 22 subjek kelompok kontrol. Desain penelitian adalah case control. Penelitian dilakukan di Kelurahan Bangetayu Kulon dan Jangli, Semarang. Data yang diteliti meliputi perilaku makan dan pola asuh pemberian makan yang diperoleh melalui kuesioner. Analisis data yang dilakukan adalah uji komparatif kategorik Chi-square.

Hasil : Kelompok balita gemuk sebagian besar memiliki skor penyuka makanan yang tinggi (95.5\%), sedangkan dari kelompok non gemuk tidak terdapat balita dengan skor penyuka makanan tinggi (0.0\%). Sementara itu, skor penghindar cenderung tinggi pada kelompok non gemuk (72.7\%), sedangkan kelompok gemuk dengan skor penghindar makanan tinggi berjumlah lebih sedikit (27.3\%). Pola asuh pemberian makan yang dominan pada kelompok gemuk adalah tipe pengabaian (59.0\%), sedangkan pada kelompok non-gemuk adalah tipe demokratis (54.5\%). Terdapat perbedaan perilaku penyuka makanan $(p<0.01)$, perilaku penghindar makanan $(p=0.07)$ dan pola asuh pemberian makan antara kedua kelompok ( $p<0.01)$.

Simpulan : Terdapat perbedaan perilaku penyuka makanan, perilaku penghindar makanan dan pola asuh pemberian makan antara balita gemuk dan non-gemuk di Kota Semarang.
\end{abstract}

Kata kunci : balita, kegemukan, perilaku makan, pola asuh pemberian makan

\section{PENDAHULUAN}

Kejadian kegemukan kini tidak hanya ditemukan pada orang dewasa saja melainkan juga pada balita. Usia dua sampai lima tahun merupakan masa dimana balita mulai aktif dalam memilih makanan sehingga sudah dapat memilih sendiri makanan yang diinginkan. ${ }^{1}$ Kegemukan yang terjadi pada balita memiliki berbagai dampak merugikan bahkan hingga balita tersebut berusia dewasa. ${ }^{2}$ Dampak kegemukan pada balita diantaranya adalah gangguan gerak dan tumbuh kembang akibat timbunan lemak yang berlebihan, obstruktive sleep apnea, gangguan kulit berupa sering lecet karena gesekan, gerah atau panas, biang keringat, maupun jamur pada lipatan-lipatan kulit. ${ }^{3,4}$ Pada masa dewasa, balita yang memiliki riwayat kegemukan berisiko mengalami penyakit degeratif seperti penyakit kardiovaskuler, diabetes tipe dua, gangguan fungsi paru, serta gangguan ortopedik. ${ }^{2}$ 
Berdasarkan data Riset Kesehatan Dasar tahun 2013, balita yang mengalami kelebihan berat badan mencapai $11,9 \% .5$ Sementara itu, data Dinas Kesehatan Kota Semarang menunjukkan bahwa prevalensi gizi lebih pada balita semakin meningkat dari tahun 2012 hingga 2014, yaitu dari 0,18\% pada tahun $2012,{ }^{6}$ meningkat menjadi $2,09 \%$ pada tahun $2013,{ }^{7}$ dan meningkat kembali menjadi $4,75 \%$ pada tahun $2014 .{ }^{8}$ Penanganan balita gemuk di Indonesia perlu mendapat perhatian khusus meskipun belum menjadi masalah gizi utama karena prevalensinya yang terus meningkat dari tahun ke tahun.

Ada berbagai macam faktor risiko kegemukan pada balita yang dapat dimodifikasi dalam lingkungan keluarga, salah satunya adalah perilaku makan. Perilaku makan dapat dibagi menjadi dua golongan besar, yaitu penyuka makanan (food approach) dan penghindar makanan (food avoidant) ${ }^{9,10}$ Beberapa penelitian telah menyatakan bahwa terdapat hubungan antara perilaku makan dengan status gizi balita. ${ }^{9,11}$ Perilaku makan balita dapat menggambarkan ketertarikan terhadap makanan, keinginan untuk makan, perasaan saat makan, keinginan untuk minum, kecepatan saat makan, dan pemilihan jenis makanan baru. ${ }^{12}$ Balita yang mengalami kegemukan cenderung menghabiskan makanan lebih cepat, kurang sensitif terhadap rasa kenyang dan lebih rensponsif terhadap makanan dibandingkan balita dengan berat badan normal. ${ }^{13}$ Perilaku makan balita akan mempengaruhi asupan energi melalui pilihan tentang kapan dan di mana untuk makan, jenis dan jumlah makanan yang dipilih, termasuk keputusan untuk memulai dan menghentikan makan. ${ }^{14}$

Faktor penyebab kegemukan lainnya adalah pola asuh pemberian makan yang dapat dibagi menjadi empat tipe yaitu demokratis, otoriter, permisif, dan pengabaian. ${ }^{15}$ Tipe-tipe tersebut merupakan hasil kombinasi dari dua aspek yaitu demandingness (D) yang menunjukkan seberapa besar peran orang tua dalam menuntut anak untuk makan, mengontrol jumlah dan jenis asupan anak serta aspek responssiveness $(\mathrm{R})$ yang menunjukkan seberapa besar peran orang tua dalam mendampingi anak dan tanggap terhadap kebutuhan anak terkait makan. ${ }^{16,17}$ Pada dasarnya, setiap tipe pola asuh pemberian makan berisiko untuk meningkatkan berat badan balita. ${ }^{18}$ Berdasarkan hasil sejumlah penelitian dinyatakan bahwa orang tua dengan pola asuh permisif dan pengabaian berisiko lebih tinggi menyebabkan balita mengalami kegemukan. ${ }^{19,20}$ Pada penelitian lain, penerapan pola asuh otoriter dinyatakan berisiko mengakibatkan balita mengalami malnutrisi baik gizi lebih maupun gizi kurang. ${ }^{21}$ Sementara itu, tipe pola asuh demokratis dikatakan sebagai pola asuh yang paling seimbang dan sehat karena orang tua yang menerapkan pola asuh ini cenderung memiliki anak dengan status gizi normal. ${ }^{15}$ Namun, pada penerapan pola asuh demokratis tetap terdapat risiko terjadinya kegemukan pada anak apabila orang tua belum memiliki pengetahuan gizi yang baik. ${ }^{3}$

Penelitian mengenai perilaku makan dan pola asuh pemberian makan yang dikaitkan dengan kegemukan pada balita telah banyak dilakukan di berbagai negara maju, sedangkan di Indonesia khususnya Semarang masih jarang ditemukan informasi mengenai penelitian serupa. Berdasarkan uraian di atas, maka dapat dikembangkan penelitian mengenai perbedaan perilaku makan dan pola asuh pemberian makan antara balita gemuk dan balita non gemuk di Kota Semarang. Penelitian ini diharapkan dapat memberikan informasi untuk membantu menangani kasus kegemukan balita di Kota Semarang dengan memperhatikan perilaku makan dan pola asuh, sehingga dapat diterapkan program penanganan yang lebih tepat.

\section{METODE PENELITIAN}

Penelitian ini termasuk dalam lingkup gizi masyarakat dengan desain case control. Pelaksanaan penelitian dilakukan pada bulan Agustus - Oktober 2016. Populasi penelitian dipilih berdasarkan wilayah dengan angka prevalensi kegemukan balita tertinggi di Kota Semarang, yaitu Kelurahan Bangetayu. Jumlah sampel minimal yaitu sebanyak 44 sampel yang terdiri atas 22 sampel kelompok kasus (gemuk) dan 22 sampel kelompok kontrol (non gemuk). Pemilihan sampel diperluas di Kelurahan Jangli untuk memenuhi jumlah sampel minimal. Kriteria inklusi dalam penelitian ini yaitu pasangan ibu dan balita berusia dua sampai lima tahun terhitung dari 1 Juli 2016, bertempat tinggal di Kelurahan Bangetayu dan Jangli, ibu bersedia menjadi subjek penelitian yang dibuktikan dengan mengisi informed consent, pada kelompok kasus dipilih balita dengan z-score $\mathrm{BB} / \mathrm{TB}>+2 \mathrm{SD}$, pada kelompok kontrol dipilih balita dengan z-score BB/TB -2 SD sampai dengan +2 SD. Skrining dilakukan saat pelaksanaan posyandu di masing-masing RW. Tahap selanjutnya adalah melakukan random sampling untuk diambil subjek sebanyak yang dibutuhkan.

Variabel bebas dalam penelitian ini adalah perilaku makan dan pola asuh pemberian makan, sedangkan variabel terikatnya adalah kegemukan pada balita. Perilaku makan didefinisikan sebagai cara yang ditempuh balita dalam memilih makanan dan memakannya. ${ }^{22}$ Penyuka makanan merupakan suatu kondisi dimana anak menyukai makanan atas dasar ketertarikan pada makanan, keinginan untuk selalu makan, asupan makan yang bertambah karena pengaruh emosional, dan keinginan untuk selalu 
minum. Penghindar makanan adalah suatu kondisi dimana anak kurang tertarik terhadap makanan atas dasar nafsu makan yang sedikit, mudah merasa kenyang, berkurangnya kecepatan saat makan, asupan makanan yang berkurang karna pengaruh emosional, serta hanya menyukai jenis makanan tertentu dan menolak jenis makanan baru. ${ }^{12}$ Sementara itu, pola asuh pemberian makan merupakan praktik pengasuhan yang diterapkan orang tua kepada anaknya berkaitan dengan pemberian makanan yang dibagi menjadi tipe demokratis, otoriter, permisif, dan pengabaian. ${ }^{23}$ Pola asuh demokratis yaitu dimana orang tua menuntut anak untuk makan, menetukan menu makanan, tetapi tetap memberikan kesempatan bagi anak memilih makanan. Pola asuh otoriter yaitu orang tua memiliki tuntutan yang tinggi terhadap anak untuk makan, anak hanya diizinkan menyantap makanan yang lolos seleksi orang tuanya. Pola asuh permisif adalah dimana orang tua berusaha memenuhi apa yang diinginkan anak dan cenderung memanjakan, anak diizinkan mengkonsumsi apapun yang diinginkan. Pola asuh pengabaian yaitu dimana rendahnya keterlibatan orang tua dalam memperhatikan makanan anak, kendali makanan yang masuk ke tubuh anak dikendalikan oleh anak itu sendiri tanpa ada kontrol dari orang tua. ${ }^{17}$

Data identitas subjek diperoleh melalui wawancara. Identitas ibu meliputi usia, pendidikan terakhir, pekerjaan, dan pendapatan kepala keluarga. Identitas balita meliputi usia, jenis kelamin, dan riwayat penyakit yang diderita. Data perilaku makan balita diperoleh dari pengisian kuesioner yang terdiri dari 35 butir pertanyaan dengan skala likert. Setiap butir memiliki 5 kemungkinan jawaban yaitu tidak pernah (1), jarang (2), kadang-kadang (3), sering (4), selalu (5). Balita dikatakan memiliki perilaku penyuka makanan apabila hasil skor pertanyaan penyuka makanan tinggi ( $>$ median), sedangkan balita dikatakan memiliki perilaku penghindar makanan apabila hasil skor pertanyaan penghindar makanan tinggi (> median). ${ }^{12}$ Sementara itu, data pola asuh pemberian makan diperoleh dari pengisian kuesioner dengan skala likert yang terdiri dari 24 butir pertanyaan yang dibagi menjadi 17 soal demandingness (D) dan 7 soal responsiveness (R). Setiap butir soal memiliki 5 kemungkinan jawaban, yaitu tidak pernah (0), jarang (1), kadang-kadang (2), sering (3), selalu (4). Pola asuh orang tua termasuk tipe demokratis apabila $\mathrm{D}$ dan $\mathrm{R} \geq$ median, tipe otoriter apabila $\mathrm{D} \geq$ median tetapi $\mathrm{R}<$ median, tipe permisif apabila $\mathrm{D}<$ median tetapi $\mathrm{R} \geq$ median, dan tipe pengabaian apabila D dan $\mathrm{R}<$ median. ${ }^{15}$ Analisis data dilakukan menggunakan program SPSS versi 16 dengan derajat kepercayaan 95\% $(\alpha=0.05)$. Dilakukan uji komparatif kategorik Chi-Square untuk melihat perbedaan perilaku makan dan pola asuh pemberian makan antara kelompok balita gemuk dan non gemuk.

\section{HASIL}

\section{Karakteristik Subjek Penelitian}

Subjek penelitian terdiri dari 26 balita perempuan dan 18 balita laki-laki. Tidak terdapat perbedaan karakteristik subjek penelitian, kecuali pada berat badan dan z-score BB/TB sebagai indikator dari variabel yang diteliti (Tabel 1). Rerata berat badan kelompok gemuk lebih tinggi (21.9 \pm 4.47$)$ dibandingkan kelompok non gemuk (14 \pm 2.17$)$. Rerata $z$-score BB/TB lebih tinggi pada kelompok gemuk $(3.97 \pm 1.23)$ dibandingkan kelompok non gemuk $(-0.05 \pm 1.03)$.

Tabel 1. Karakteristik Subjek Penelitian

\begin{tabular}{|c|c|c|c|c|c|}
\hline \multirow{2}{*}{ Variabel } & \multicolumn{2}{|c|}{$\begin{array}{l}\text { Gemuk } \\
(n=22)\end{array}$} & \multicolumn{2}{|c|}{$\begin{array}{c}\text { Non Gemuk } \\
(n=22)\end{array}$} & \multirow[b]{2}{*}{$p$} \\
\hline & Rerata \pm SD & $\begin{array}{c}\text { Median } \\
\text { (Min, Max) }\end{array}$ & Rerata \pm SD & $\begin{array}{c}\text { Median } \\
\text { (Min, Max) }\end{array}$ & \\
\hline Usia balita (bulan) & $46.0 \pm 9.63$ & $\begin{array}{c}49.0 \\
(25.0,59)\end{array}$ & $46.0 \pm 8.40$ & $\begin{array}{c}48.5 \\
(31.0,59.0)\end{array}$ & $1.000^{\mathrm{a}}$ \\
\hline Berat Badan (kg) & $21.9 \pm 4.47$ & $\begin{array}{c}20.0 \\
(16.0,31.9)\end{array}$ & $14.0 \pm 2.17$ & $\begin{array}{c}14.1 \\
(10.0,19.0)\end{array}$ & $<0.01^{\mathrm{a}}$ \\
\hline Tinggi Badan $(\mathrm{cm})$ & $99.1 \pm 8.89$ & $\begin{array}{c}100.0 \\
(81.5,111.6)\end{array}$ & $95.7 \pm 6.46$ & $\begin{array}{c}96.9 \\
(82.7,110.0)\end{array}$ & $0.154^{\mathrm{a}}$ \\
\hline Z-score BB/TB & $3.9 \pm 1.23$ & $\begin{array}{c}3.8 \\
(2.2,6.2)\end{array}$ & $-0.05 \pm 1.03$ & $\begin{array}{c}-0.1 \\
(-1.6,2.0)\end{array}$ & $<0.01^{\mathrm{a}}$ \\
\hline
\end{tabular}

a Independent T test

Karakteristik demografi subjek dapat dilihat pada tabel 2. Hasil uji statistik menunjukkan bahwa tidak terdapat perbedaan pada karakteristik demografi yang meliputi jenis kelamin balita, tingkat pendidikan ibu, pekerjaan ibu, dan tingkat pendapatan kepala keluarga. 
Tabel 2. Karakteristik Demografi Subjek

\begin{tabular}{|c|c|c|c|}
\hline Variabel & $\begin{array}{c}\text { Gemuk } \\
\text { n (\%) }\end{array}$ & $\begin{array}{c}\text { Non Gemuk } \\
\text { n (\%) } \\
\end{array}$ & $p$ \\
\hline \multicolumn{4}{|l|}{ Jenis Kelamin Balita } \\
\hline Laki-laki & $9(40.9)$ & $9(40.9)$ & \multirow{2}{*}{$1.000^{\mathrm{b}}$} \\
\hline Perempuan & $13(59.1)$ & $13(59.1)$ & \\
\hline \multicolumn{4}{|l|}{ Tingkat Pendidikan Ibu } \\
\hline Rendah (tidak sekolah, SD, SMP) & $9(40.9)$ & $12(54.5)$ & \multirow{2}{*}{$0.546^{\mathrm{b}}$} \\
\hline Tinggi (SMA, S1, S2) & $13(59.1)$ & $10(45.4)$ & \\
\hline \multicolumn{4}{|l|}{ Pekerjaan Ibu } \\
\hline Bekerja & $13(59.1)$ & $10(45.4)$ & \multirow{2}{*}{$0.546^{\mathrm{b}}$} \\
\hline Tidak bekerja & $9(40.9)$ & $12(54.5)$ & \\
\hline \multicolumn{4}{|l|}{ Tingkat Pendapatan Kepala Keluarga** } \\
\hline Rendah $(<\operatorname{Rp} 1.900 .000,-)$ & $7(31.8)$ & $11(50.0)$ & \multirow{2}{*}{$0.358^{\mathrm{b}}$} \\
\hline Tinggi ( $\geq$ Rp $1.900 .000,-)$ & $15(68.2)$ & $11(50.0)$ & \\
\hline
\end{tabular}

${ }^{\mathrm{b}}$ komparatif kategorik Chi-square

Perbedaan Perilaku Makan antara Balita Gemuk dan Non Gemuk

Hasil uji statistik menunjukkan terdapat perbedaan yang bermakna pada perilaku penyuka makanan $(p<0.01)$ dan penghindar makanan $(p=0.007)$ antara kelompok gemuk dan non gemuk. Kelompok balita gemuk sebagian besar memiliki skor penyuka makanan yang tinggi (95.5\%), sedangkan dari kelompok non gemuk tidak terdapat balita dengan skor penyuka makanan tinggi $(0.0 \%)$. Sementara itu, skor penghindar makanan cenderung tinggi pada kelompok non gemuk (72.7\%), sedangkan kelompok gemuk dengan skor penghindar makanan tinggi hanya sebesar $27.3 \%$. (Tabel 3).

Tabel 3. Perbedaan Perilaku Makan antara Balita Gemuk dan Non Gemuk

\begin{tabular}{cccc}
\hline Perilaku Makan & Gemuk & Non Gemuk & \multirow{2}{*}{ n $(\%)$} \\
\cline { 2 - 3 } Penyuka Makanan & $\mathrm{n}(\%)$ & $22(100)$ & $<0.01^{\mathrm{b}}$ \\
Rendah & $1(4.5)$ & $0(0.0)$ & \\
Tinggi & $2195.5)$ & & \\
Penghindar Makanan & & $6(27.3)$ & $0.007^{\mathrm{b}}$ \\
Rendah & $16(72.7)$ & $16(72.7)$ & \\
Tinggi & $6(27.3)$ & & \\
\hline
\end{tabular}

${ }^{\mathrm{b}}$ komparatif kategorik Chi-square

Jawaban kuesioner perilaku makan menunjukkan bahwa balita kelompok gemuk cenderung memiliki ketertarikan yang tinggi terhadap makanan. Sementara itu, balita kelompok non gemuk memiliki ketertarikan terhadap makanan yang lebih rendah dibandingkan dengan kelompok gemuk (Tabel 4).

Tabel 4. Perbedaan Skor Kuesioner Perilaku Makan Kategori Jawaban Sering dan Selalu pada Kelompok Gemuk dan Non Gemuk

\begin{tabular}{lcc}
\hline \multicolumn{1}{c}{ Kuesioner Perilaku Makan } & Gemuk & $\begin{array}{c}\text { Non } \\
\text { Gemuk }\end{array}$ \\
\hline $\begin{array}{l}\text { Penyuka Makanan } \\
\text { "Anak saya selalu meminta makan" }\end{array}$ & 16 & 0 \\
"Jika diperbolehkan, anak saya akan makan banyak sekali" & 14 & 0 \\
"Anak saya menantikan waktu makan" & 9 & 1 \\
"Walaupun sudah kenyang, anak saya akan menemukan lokasi (tempat) & 13 & 2 \\
untuk makan makanan kesukaannya" & & 2 \\
"Jika diberi kesempatan, anak saya akan terus mengunyah makanan di & 12 & \\
Penghindar Makanan & & 8 \\
"Anak saya makan dengan lambat" & & 12 \\
"Anak saya menyisakan makanan di piring sehabis makan" & 4 & 7 \\
\hline
\end{tabular}


Perbedaan Pola Asuh Pemberian Makan antara Balita Gemuk dan Non Gemuk

Tabel 5 menunjukkan terdapat perbedaan pola asuh pada aspek demandingness antara kelompok gemuk dan non gemuk $(p<0.01)$. Sementara itu, pada aspek responsiveness tidak terdapat perbedaan antara kelompok gemuk dan non gemuk ( $p=0.07)$. Ibu dari kelompok gemuk sebagian besar memiliki demandingness dan responsiveness yang rendah (81.8\% dan 63.6\%). Sementara itu, ibu dari kelompok non gemuk sebagian besar memiliki demandingness dan responsiveness yang tinggi (81.8\% dan $68.2 \%)$.

Tabel 5. Karakteristik Pola Asuh Pemberian Makan antara Balita Gemuk dan Non Gemuk

\begin{tabular}{cccc}
\hline \multirow{2}{*}{ Aspek Pola Asuh Pemberian Makan } & Gemuk & Non Gemuk & \multirow{2}{*}{$\boldsymbol{p}$} \\
\cline { 2 - 3 } Demandingness & $\mathrm{n}(\%)$ & & \\
Rendah & & & $<0.01^{\mathrm{b}}$ \\
Tinggi & $18(81.8)$ & $18(8.2)$ & \\
Responsiveness & $4(18.2)$ & & \\
Rendah & & $7(31.8)$ & $0.07^{\mathrm{b}}$ \\
Tinggi & $14(63.6)$ & $15(68.2)$ & \\
\hline
\end{tabular}

${ }^{\mathrm{b}}$ komparatif kategorik Chi-square

Pada kelompok gemuk, ibu memiliki demandingness rendah yang menunjukkan bahwa ibu jarang menuntut anak untuk makan. Sementara itu, ibu dari kelompok non gemuk memiliki demandingness tinggi yang menunjukkan bahwa ibu berusaha menuntut anak untuk makan. Skor aspek responsiveness tidak berbeda jauh antara kelompok gemuk dan non gemuk, tetapi kelompok non gemuk memiliki skor yang lebih tinggi (Tabel 6).

Tabel 6. Perbedaan Skor Kuesioner Pola Asuh Pemberian Makan Kategori Jawaban Sering dan Selalu antara Kelompok Gemuk dan Non Gemuk

\begin{tabular}{lcc}
\hline \multicolumn{1}{c}{ Kuesioner Pola Asuh Pemberian Makan } & Gemuk & Non Gemuk \\
\hline $\begin{array}{l}\text { Demandingness } \\
\text { "Ibu berusaha dengan keras untuk menyuruh anak makan" }\end{array}$ & 9 \\
"Ibu berusaha mengingatkan anak untuk makan, jika tidak mau & 1 & 15 \\
makan, ibu yang mengambilkan makanannya" & \\
"Ibu menjanjikan sesuatu (selain makanan) jika anak bersedia & 0 & 8 \\
makan" & & 15 \\
"Ibu menunjukkan ketidaksetujuan ketika anak menolak untuk & 2 & 15 \\
makan" & & 14 \\
"Ibu membantu anak untuk makan" & 9 & 14 \\
"Ibu memberikan pujian kepada anak ketika makan" & 11 & 11 \\
\hline
\end{tabular}

Berdasarkan kombinasi dari aspek kelompok gemuk dan non gemuk $(p<0.01)$. Pada demandingness dan responsiveness, maka dapat kelompok gemuk pola asuh yang paling dominan ditentukan empat macam tipe pola asuh, yaitu adalah tipe pengabaian (59.0\%), sedangkan pada demokratis, otoriter, permisif, dan pengabaian. Hasil kelompok non gemuk pola asuh yang paling dominan uji statistik menunjukkan terdapat perbedaan yang adalah tipe demokratis (54.5\%) (Tabel 7). signifikan pada pola asuh pemberian makan antara

Tabel 7. Perbedaan Tipe Pola Asuh Pemberian Makan antara Balita Gemuk dan Non Gemuk

\begin{tabular}{lccc}
\hline \multirow{2}{*}{ Pola asuh pemberian makan } & Gemuk & Non Gemuk & \multirow{2}{*}{$\boldsymbol{p}$} \\
\cline { 2 - 3 } & n $(\%)$ & $12(54.5)$ & \\
\hline Demokratis & $3(13.6)$ & $7(31.8)$ & $<0.01^{\mathrm{c}}$ \\
Otoriter & $1(4.5)$ & $1(4.5)$ & \\
Permisif & $5(22.7)$ & $2(9.1)$ & \\
Pengabaian & $13(59.0)$ & & \\
\hline
\end{tabular}

${ }^{c}$ kruskal-walis 
Perilaku makan dan pola asuh pemberian makan merupakan dua faktor yang dapat saling mempengaruhi satu sama lain sebagai penyebab kegemukan pada balita. Balita yang diasuh dengan tipe demokratis sebagian besar memiliki perilaku penyuka makanan rendah (56.5\%) dan penghindar makanan tinggi (45.4\%). Sementara itu, orang tua yang menerapkan pola asuh pengabaian cenderung memiliki anak dengan perilaku penyuka makanan tinggi $(61.9 \%)$ dan penghindar makanan rendah $(50.0 \%)$ (Tabel 8).

Tabel 8. Perbedaan Pola Asuh Pemberian Makan antara Penyuka Makanan dan Penghindar Makanan

\begin{tabular}{|c|c|c|c|c|c|c|c|}
\hline \multirow{2}{*}{$\begin{array}{c}\text { Pola asuh } \\
\text { pemberian } \\
\text { makan }\end{array}$} & $\begin{array}{c}\text { Penyuka } \\
\text { Makanan } \\
\text { Tinggi } \\
\end{array}$ & $\begin{array}{c}\text { Penyuka } \\
\text { Makanan } \\
\text { Rendah }\end{array}$ & \multirow[t]{2}{*}{$p$} & \multirow{2}{*}{$\begin{array}{c}\text { Pola asuh } \\
\text { pemberian } \\
\text { makan }\end{array}$} & $\begin{array}{c}\text { Penghindar } \\
\text { Makanan } \\
\text { Tinggi } \\
\end{array}$ & $\begin{array}{c}\text { Penghindar } \\
\text { Makanan } \\
\text { Rendah }\end{array}$ & \multirow[t]{2}{*}{$p$} \\
\hline & n (\%) & n (\%) & & & n (\%) & n (\%) & \\
\hline Demokratis & $2(9.5)$ & $13(56.5)$ & \multirow{4}{*}{$<0.01^{\mathrm{c}}$} & Demokratis & $10(45.4)$ & $5(22.7)$ & \multirow{4}{*}{$0.04^{\mathrm{c}}$} \\
\hline Otoriter & $1(4.7)$ & $7(30.4)$ & & Otoriter & $4(18.2)$ & $4(18.2)$ & \\
\hline Permisif & $5(23.8)$ & $1(4.3)$ & & Permisif & $4(18.2)$ & $2(9.1)$ & \\
\hline Pengabaian & $13(61.9)$ & $2(8.7)$ & & Pengabaian & $6(27.3)$ & $11(50.0)$ & \\
\hline
\end{tabular}

ckruskal-walis

\section{PEMBAHASAN}

Salah satu faktor penyebab kegemukan pada balita adalah perilaku makan., ${ }^{9,10,11}$ Hasil penelitian menunjukkan terdapat perbedaan yang bermakna pada perilaku penyuka makanan $(p<0.01)$ dan penghindar makanan antara kelompok gemuk dan non gemuk $(p=0.04)$. Hasil perhitungan kuesioner menunjukkan bahwa kelompok gemuk memiliki ketertarikan terhadap makanan yang lebih tinggi dibandingkan kelompok non gemuk. Dari hasil wawancara diketahui kelompok gemuk umumnya menyukai makanan dan minuman yang memiliki kadar kalori dan gula yang tinggi seperti roti, sosis, siomay, susu, coklat, es krim, permen, serta minuman manis, sehingga memicu terjadinya kegemukan.

Faktor lainnya yang dapat menyebabkan kegemukan pada balita adalah pola asuh pemberian makan. Hasil penelitian menunjukkan terdapat perbedaan tipe pola asuh pemberian makan antara kelompok gemuk dan non gemuk $(p<0.01)$. Hasil uji statistik juga menunjukkan bahwa terdapat perbedaan pada aspek demandingness antara kelompok gemuk dan non gemuk $(p<0.01)$. Sementara itu, tidak terdapat perbedaan yang bermakna pada aspek responsiveness antara kedua kelompok, tetapi dengan nilai $p$ value yang masih cukup rendah secara statistik yaitu $p=0.07$. Berdasarkan hasil wawancara, pada umumnya ibu dari kedua kelompok menunjukkan sikap responsiveness dengan memberikan pujian ketika anak makan, membantu anak makan, dan mengizinkan anak untuk mengambil serta memilih makanannya sendiri. Namun, sikap responsiveness ini lebih tinggi ditemukan pada ibu kelompok non gemuk dibandingkan dengan ibu kelompok gemuk, meskipun dengan selisih yang tidak jauh berbeda.

Perilaku makan dan pola asuh pemberian makan merupakan dua faktor penyebab kegemukan pada balita yang dapat saling mempengaruhi dan berkaitan erat dengan lingkungan keluarga. ${ }^{24,25}$ Pada kelompok gemuk, mayoritas balita merupakan penyuka makanan. Perilaku makan balita dapat dipengaruhi oleh faktor genetik maupun lingkungan, salah satunya yaitu pola asuh orang tua. ${ }^{9,24}$ Hasil penelitian menunjukkan bahwa mayoritas ibu dari kelompok gemuk menerapkan pola asuh tipe pengabaian, yaitu sebanyak 13 (59\%) subjek. Hal ini sejalan dengan penelitian yang dilakukan oleh Astuti pada anak pra sekolah usia 3-6 tahun di Kota Megelang, dimana balita obesitas sebagian besar di asuh dengan tipe pengabaian $(44 \%){ }^{20}$

Pola asuh tipe pengabaian merupakan kombinasi dari aspek demandingness rendah dan responsiveness rendah. Demandingness rendah menunjukkan kurangnya peran ibu dalam menuntut anak untuk makan, sedangkan responsiveness rendah menunjukkan bahwa ibu kurang tanggap dalam memenuhi kebutuhan anak terkait makan. ${ }^{26}$ Kendali makanan yang masuk ke tubuh anak dikendalikan oleh anak itu sendiri karena kurangnya kontrol, tuntutan dan arahan dari orang tua, sementara makanan yang disukai anak adalah yang mengandung kalori dan gula tinggi, maka anak berisiko mengalami kegemukan. ${ }^{20,27}$ Namun, pernyataan-pernyataan kuesioner pola asuh pemberian makan yang digunakan peneliti kurang dapat menggambarkan apakah orang tua juga mengontrol jenis dan jumlah asupan anak. Pernyataan-pernyataan pada aspek demandingness mengarah pada tuntutan orang tua agar anak mau makan, bukan tuntutan untuk mengontrol jenis dan jumlah asupan anak.

Kurangnya peran ibu dalam dalam menuntut anak untuk makan pada kelompok gemuk juga dapat dikatakan sebagai respon ibu terhadap anak yang memiliki perilaku penyuka makanan. Balita kelompok gemuk umumnya selalu meminta makan, makan dalam jumlah yang banyak, menantikan waktu makan, serta tetap ingin makan walaupun sudah kenyang. Perilaku tersebut kemungkinan 
menyebabkan ibu jarang mengontrol dan menuntut anak untuk makan, karena anak dengan sendirinya akan meminta makan tanpa perlu dituntut. Oleh karena itu, mungkin sikap ibu yang jarang menuntut untuk makan pada anak penyuka makanan sebenarnya sudah merupakan sikap yang tepat untuk mengendalikan berat badan anak. Apabila ibu menyadari anaknya memiliki ketertarikan yang tinggi terhadap makanan, menuntutnya untuk makan justru semakin meningkatkan risiko kegemukan pada anak.

Pada kelompok non gemuk, semua balita memiliki skor perilaku penyuka makanan yang rendah $(100.0 \%)$ dan skor penghindar makanan yang tinggi $(72.7 \%)$. Berdasarkan hasil wawancara, diketahui bahwa kelompok balita non gemuk umumnya menghabiskan makanan dengan lambat, menyisakan makanan di piring, dan cepat merasa kenyang. Dalam suatu penelitian yang dilakukan oleh Lubis, dinyatakan bahwa ritme kecepatan saat mengunyah makanan sangat berpengaruh pada kesehatan dan berat badan. Mengunyah dengan pelan akan membantu tubuh untuk menyerap zat gizi dengan lebih efektif, memperbaiki sistem pencernaan, dan mengontrol nafsu makan. ${ }^{28} \mathrm{Hal}$ tersebut dapat menjadi alasan mengapa balita yang makan dengan lambat dominan pada kelompok non gemuk, karena makan dengan lambat dapat membantu membatasi kalori yang masuk ke dalam tubuh, sehingga berat badan dapat terkendali.

Hasil penelitian ini juga menunjukkan bahwa pola asuh yang dominan pada kelompok non gemuk adalah tipe demokratis $(54.5 \%)$, yaitu tipe dimana terdapat keseimbangan antara aspek demandingness dan responsiveness yang keduanya tinggi $(81.8 \%$ dan $68.2 \%$ ). Ibu memiliki tuntutan yang tinggi terhadap anak untuk makan, tetapi diimbangi dengan sikap responsif yang juga tinggi, sehingga anak merasa nyaman dan senantiasa menghabiskan makanannya tanpa merasa tertekan. Penerapan pola asuh demokratis pada kelompok non gemuk kemungkinan merupakan respon ibu terhadap perilaku penghindar makanan, sehingga ibu berusaha untuk memantau dan mengontrol kebiasaan makan anak karena khawatir anaknya akan mengalami gizi kurang. Hal ini sejalan dengan penelitian yang dilakukan oleh Wardle, dimana ibu menganggap perilaku penghindar makanan pada anak sebagai suatu masalah sehingga ibu berusaha mengontrol asupan anak. ${ }^{12}$ Ibu yang menerapkan pola asuh demokratis juga memberikan kesempatan bagi anak untuk memilih makanan yang disukainya, tetapi tetap mendapat pengawasan. Pola asuh demokratis dikatakan sebagai pola asuh yang paling ideal terutama bagi balita yang sedang mengalami masa pertumbuhan dan perkembangan. Adanya diskusi antara orang tua dan anak perihal makan berperan efektif untuk mengontrol asupan anak karena orang tua memperhatikan kebutuhan keseimbangan gizi, sehingga pertumbuhan anak ideal dan risiko kegemukan dapat berkurang. ${ }^{29,30}$

Dalam kehidupan sehari-hari sebenarnya pola asuh yang diterapkan orang tua dapat bersifat multidimensional. Artinya, meskipun orang tua menerapkan pola asuh demokratis, pada situasi tertentu orang tua bisa saja menggunakan pola asuh otoriter ataupun permisif. Penerapan tipe pola asuh dapat dipengaruhi oleh berbagai faktor sosial maupun lingkungan, termasuk perilaku makan balita. ${ }^{27}$ Perilaku penghindar makanan pada balita non gemuk apabila berlangsung dalam waktu yang lama dapat menjadi gangguan makan yang serius karena balita bisa mengalami gizi kurang maupun defisiensi zat gizi tertentu. ${ }^{31,32}$ Pada kasus tersebut, orang tua perlu bersikap otoriter jika meningkatkan tuntutan terhadap anak untuk makan dianggap efektif untuk mempertahankan status gizi normal. Namun, pada kasus yang sama dengan kondisi yang berbeda, orang tua perlu menerapkan pola asuh permisif jika anak dianggap membutuhkan suasana makan yang lebih menyenangkan dan sikap orang tua yang lebih responsif agar dapat mempertahankan status gizi normal. Oleh sebab itu, orang tua perlu menerapkan pola asuh yang mereka anggap paling tepat bagi anak mereka, karena pola asuh akan sangat berpengaruh terhadap pertumbuhan dan perkembangan anak. Orang tua dapat melakukan adaptasi pada tipe pola asuh yang diterapkan menyesuaikan dengan situasi dan kondisi agar dapat mempertahankan status gizi normal pada anak.

\section{KETERBATASAN PENELITIAN}

Pada variabel pola asuh pemberian makan aspek demandingness, kuesioner yang digunakan peneliti telah menggambarkan tuntutan dan kontrol orang tua terhadap anak untuk makan, tetapi kurang dapat menggambarkan apakah orang tua melakukan kontrol terhadap jumlah dan jenis asupan yang dapat menyebabkan kegemukan, sehingga kurang relevan untuk menilai pola asuh sebagai penyebab kegemukan pada balita. Penggunaan kuesioner lain yang lebih relevan mungkin akan diperoleh hasil yang berbeda dari penelitian ini.

\section{SIMPULAN}

Terdapat perbedaan perilaku penyuka makanan dan penghindar makanan antara balita gemuk dan non gemuk di Kota Semarang. Kelompok gemuk sebagian besar memiliki skor penyuka makanan tinggi, sedangkan kelompok non gemuk mayoritas memiliki skor penghindar makanan tinggi. Terdapat perbedaan pola asuh pemberian makan pada aspek demandingness, tetapi tidak terdapat perbedaan pada aspek responsiveness antara balita gemuk dan 
non gemuk di Kota Semarang. Pada kelompok gemuk, pola asuh yang dominan adalah tipe pengabaian, sedangkan pada kelompok non gemuk pola asuh yang dominan adalah tipe demokratis.

\section{SARAN}

1. Bagi Orang Tua

Orang tua diharapkan dapat melakukan kontrol terhadap jumlah dan jenis asupan anak, menyajikan makanan yang sehat, membatasi makanan yang kurang sehat, melibatkan anak dalam pemilihan menu makanan, berdiskusi dengan anak dalam menentukan alternatif makanan yang sehat, serta memberikan contoh mengenai konsumsi makanan yang sehat dan seimbang. Orang tua diharapkan dapat menerapkan pola asuh yang mereka anggap paling tepat bagi anak mereka menyesuaikan dengan situasi dan kondisi agar dapat mempertahankan status gizi normal pada anak .

2. Bagi Peneliti Selanjutnya

Dapat dilakukan penelitian lebih lanjut mengenai apa yang menyebabkan orang tua memiliki demandingness dan responsiveness yang tinggi atau rendah, serta apa yang menyebabkan anak memiliki perilaku penyuka makanan atau penghindar makanan, sehingga dapat diterapkan program yang lebih tepat untuk menangani kegemukan pada balita.

\section{DAFTAR PUSTAKA}

1. Tee ES. Nutrition in Malaysia : Where are we Heading ?. Malaysia Journal of Nutrition $5: 1999$.

2. Damayanti. Waspadai Kegemukan Pada Anak. 2002. Diakses dari : www.keluargasehat.com pada tanggal 29 Maret 2016.

3. Manuaba. Obesitas Jangan Dianggap Remeh. 2004. Diakses dari : www.smallcrab.com pada tanggal 29 Maret 2016.

4. Apfelbacher Christian J, Loebroks Adrian, Cairns John, et al. Predictors of overweight and obesity in five to seven-year-old children in Germany: Results from cross-sectional studies. Biomed Central Public Health; volume 8:171. 2008.

5. Kementerian Kesehatan RI. Penyajian Pokok-Pokok Hasil Riset Kesehatan Dasar. Badan Penelitian dan Pengembangan Kesehatan Kementerian Kesehatan RI. 2013.

6. Dinas Kesehatan Semarang. Profil Kesehatan Kota Semarang. Dinas Kesehatan Kota Semarang 2012.

7. Dinas Kesehatan Semarang. Profil Kesehatan Kota Semarang. Dinas Kesehatan Kota Semarang 2013.

8. Dinas Kesehatan Semarang. Profil Kesehatan Kota Semarang. Dinas Kesehatan Kota Semarang 2014.

9. Jansen Pauline, et al. Children's Eating Behavior, Feeding Practices of Parents and Weight Problems in Early Childhood: Results from the Population-based
Generation R Study. International Journal of Behavioral Nutrition and Physical Activity. 2012. 9 : 130.

10. Ventura Alison K, Birch Leann L. Does Parenting Affect Children's Eating and Weight Status ? International Journal of Behavioral Nutrition and Physical Activity. 2008. 5:15.

11. Ainuki Tomomi, Akamatsu Rie. Association between Children's Appetite Patterns and Maternal Feeding Practices. Food and Nutrition Science. Scientific Research. 2011. 2 : 228-234.

12. Wardle J, Guthrie, C.A., Sanderson, S., Rapoport L. Development of Children's Eating Behavior Quesionnaire. Journal Child Psychology and Psychiatry. 2001. 42 : 963-970

13. Webber L, Hill C, Jaarsveld Van, Wardle J. Eating Behaviour and Weight in Children. International Journal of Obesity. Departement of Epidemiology and Public Health, University College London. 2009. $33: 21-28$.

14. French Simone, Epstein Leonard, Jeffery Robert, Blundell John, Wardle Jane. Eating Behavior Dimensions: Associations With Energy Intake And Body Weight : A Review. National Institutes of Health. 2012. 59 (2) : 541-549.

15. Hughes S.O., et al. Revisiting a neglected construct : Parenting Stlyes in a Child-Feeding Context. Elsevier. 2005. 44 : 83-92.

16. Baumrind D. Parenting styles and adolescent development. Encyclopedia of Adolescence. 1991. Vol.2, pp. 746-758) Garland, NY. 1991. Dalam : Johnson Rachel, Welk Greg, Maurice Pedro, Ihmels Michelle. Parenting Styles and Home Obesogenic Environments. International Journal of Environmental Research and Public Health. 2012 : 9 : 1411-1426.

17. Hughes Sheryl O, et al. Indulgent Feeding Style and Children's Weight Status in Preschool. NIH Public Access. 2008. 29(5): 403-410. doi:10.1097.

18. Baron R Kenny D. The Moderator-Mediator Variable Distinction in Social Psychological Research: Conceptual, Strategic and Statistical Considerations. Journal of Personality and Social Psychology. 1986. 51:1173-1182.

19. Cristin L Seher.Parent-child Interaction During Feeding. Public Health Nutristion. 2011. Diakses dari

http://www.todaysdietitian.com/newarchives/040511 p32.shtml. Pada tanggal 7 April 2016.

20. Astuti Wahyu. Hubungan Pola Asuh Pemberian Makan Dan Perilaku Makan Dengan Kejadian Obesitas Pada Anak Pra Sekolah Di Kota Magelang : Tesis. Magister Keperawatan Universitas Gadjah Mada. 2014.

21. Callahan Alice. What's Your Feeding Style ?. The Science of Mom. 2013. Diakses dari : https://scienceofmom.com/parenting-resources/ Pada Tanggal 5 April 2016.

22. Moreno Luis A. Epidemology of Obesity in Children and Adoloescents Prevalence and Etiology. London : Spinger. 2011. 
23. Emiralda. Pengaruh Pola Asuh Anak Terhadap Terjadinya Balita Malnutrisi di Wilayah Kerja PuskesmasMontasik Kecamatan Montasik Kabupaten Aceh Besar Tahun 2006. Universitas Sumatera Utara. 2007.

24. Ainuki Tomomi, Akamatsu Rie. Association between Children's Appetite Patterns and Maternal Feeding Practices. Food and Nutrition Science. Scientific Research. 2011. 2 : 228-234.

25. Ek Anna, et al. Associations between Parental Concerns about Preschoolers' Weight and Eating and Parental Feeding Practices: Results from Analyses of the Child Eating Behavior Questionnaire, the Child Feeding Questionnaire, and the Lifestyle Behavior Checklist. Research Article. Plos One. 2016.

26. Jansen, et al. The Dynamics of Parenting and Early Feeding, Constructs and Controversies. Queensland University of Technology. 2012.

27. Johnson Rachel, Welk Greg, Maurice Pedro, Ihmels Michelle. Parenting Styles and Home Obesogenic Environments. International Journal of Environmental Research and Public Health. 2012 : 9 : 1411-1426.

28. Lubis, Ritayani. Hubungan Pola Asuh Ibu dengan Status Gizi Anak Balita di Wilayah Kerja Puskesmas Pantai Cermin Kecamatan Tanjung Pura Kabupaten Langkat (skripsi). Universitas Sumatera Utara. 2008.

29. Diana Nur. Hubungan Makan Perlahan dengan Badan Langsing. 2016. Diakses dari : manfaat.co.id pada 11 November 2016.

30. Shocib Moh. Pola Asuh Orangtua dalam Membantu Anak Mengembangkan Disiplin Diri. Rineka Cipta : Jakarta. 2000.

31. Menzel Jessie. Avoidant-Restrictive Food Intake Disorder (ARFID). Neda Feeding Hope. 2016. Diakese dari https://www.nationaleatingdisorders.org/avoidantrestrictive-food-intake-disorder-arfid

32. Ehmke Rachel. More Than Picky Eating. Kids With a Serious Aversion to Many Foods May Need Help to Overcome Avoidance. 2016. Diakses dari : http://childmind.org/article/more-than-picky-eating/ 